\title{
Novel Current Resonance DC-DC Converter with Voltage Doubler Rectifier for Fuel Cell System
}

\author{
Hisatsugu KATO1,2, Hirofumi MATSUO2 and Yukitaka SAKAMOTO1 \\ 1Tabuchi Electric Co., LTD,Yodogawa-ku, Osaka, 532-0003,Japan \\ 2Graduate School of Science and Technology, Nagasaki University,Nagasaki, 852-8521, Japan, \\ E-mail:h.kato@zbr.co.jp
}

\begin{abstract}
This paper deals with a novel composite resonance DC-DC converter for low input voltage, large input current and high output voltage with the voltage doubler rectifier, which is developed to apply to the power conditioner of the fuel system. The proposed DC-DC converter has the current and voltage resonance functions to reduce the switching power loss . The primary and secondary sides of the converter are composed of the current resonant full bridge circuit, and voltage doubler, respectively. For this reason, the high power efficiency of this converter can be realized under the condition of a low input voltage, large input current and high output voltage.
\end{abstract}

\section{I . INTRODUCTION}

Recently, there is an increasing spread in the fuel cell system all over the world because many persons are interested in the clean energy system from the viewpoint of the ecological problem [1]. In this paper, a novel current resonance DC-DC converter is proposed and developed, in which the voltage doubler rectifier are employed to obtain the large step-up voltage ratio from the lower input voltage to the higher output one. The sufficiently high power efficiency can be achieved by using not only the composite resonance but also the full bridge circuit and voltage doubler rectifier. Furthermore, the burst oscillation control is used to improve the power efficiency and regulation of output voltage under the condition of the high input voltage and/or light load.

\section{II . CIRCUIT CONFIGURATIONN}

Fig.1 shows the proposed current resonance DC-DC converter with the voltage doubler rectifier, in which the current and voltage resonance circuits [2,3] are employed. In this figure, Q1, Q2, Q3 and Q4 are main switches of IGBTs. From Cv1 through Cv4, and $\mathrm{Ci}$ are the voltage and current resonance capacitors, respectively. L1 and L2 are inductances of the primary and secondary windings of the transformer $\mathrm{T}$. The voltage doubler rectifier is composed of the diodes D1 and D2, and capacitances Cd and Co. The MOSFET switches Q1, Q2, Q3 and Q4 are turned-on and turned-off alternatively. There exists the short dead time between the on-times of Q1, Q4, and Q2, Q3. The fuel cell system has the output capacity800w. Therefore, this proposed DC-DC converter is employed in parallel in practical use.

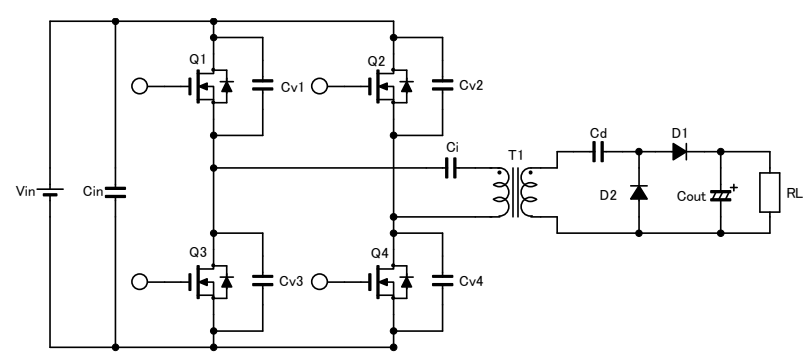

Fig.1 Novel current resonance DC- DC converter with the voltage doubler rectifier.

\section{III.WAVEFORMS}

Fig.2 shows the observed waveforms. It is seen in Fig.2 that the current resonance operation is performed well. Fig. 2 corresponds to operation Mode1 discussed in the half-bridge circuit [paper \#327]. There exists another operation mode, which corresponds to operation Mode2, as shown in Fig.3. 


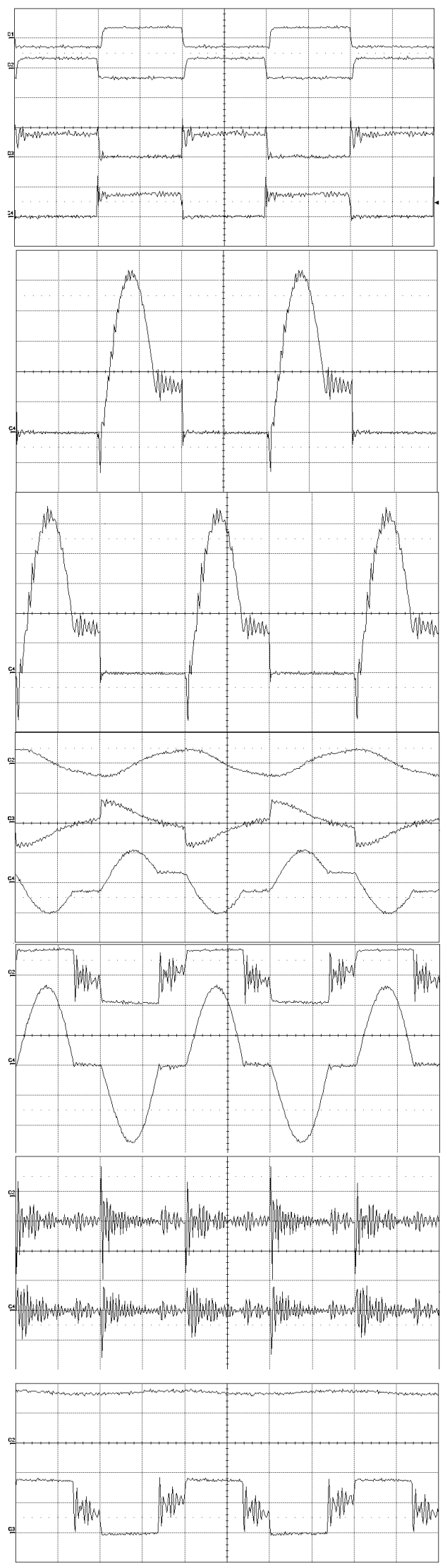

Q3 VG3 20V/div

$10 \mu \mathrm{sec} / \mathrm{div}$

Q4 VG4 20V/div

Q3 VDS3 20V/div

Q4 VDS4 20V/div

Q3 ID3 10A/div

Q4 ID4 10A/div

Voltage across Ci 50V/div

Primary winding Voltage 50V/div

Primary winding current $50 \mathrm{~A} / \mathrm{div}$

Secondary winding Voltage 350V/div

Secondary winding current $2 \mathrm{~A} / \mathrm{div}$

Current through Cv3

Current through Cv4

Voltage across Cd 200V/div

Voltage across secondary diode D2 200V/div

Fig.2 Observed waveforms 


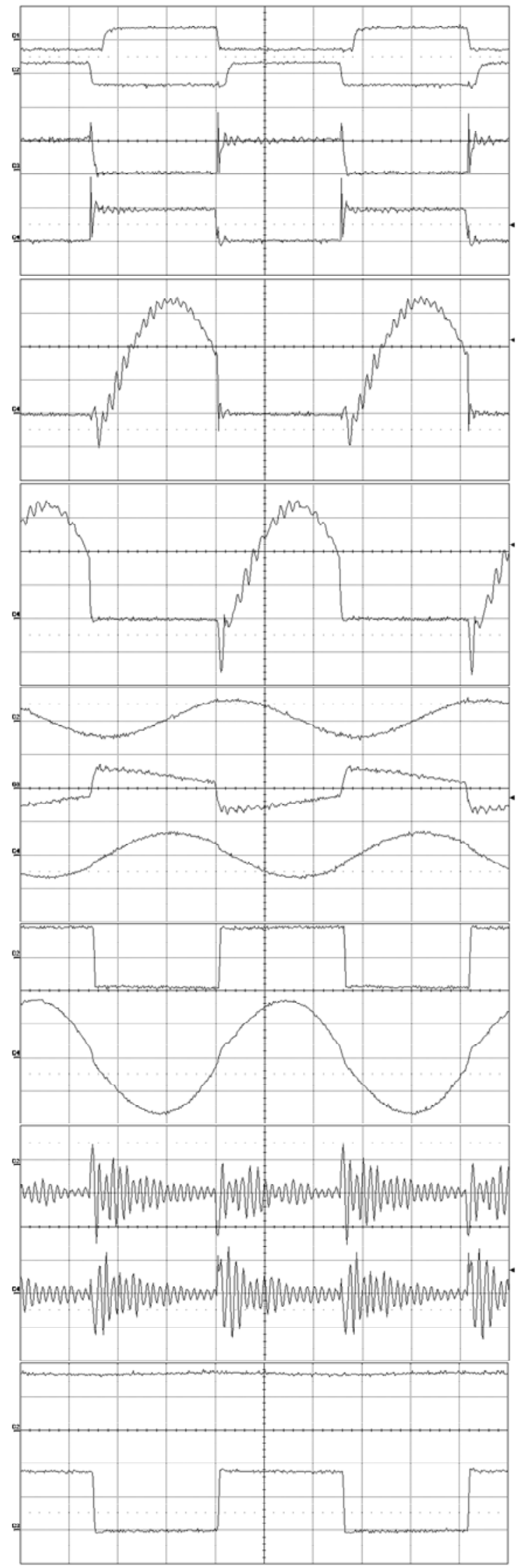

Q3 VG3 20V/div $\quad 10 \mu \mathrm{sec} / \mathrm{div}$

Q4 VG4 20V/div

Q3 VDS3 20V/div

Q4 VDS4 20V/div

Q3 ID3 10A/div

Q4 ID4 10A/div

Voltage across Ci 50V/div

Primary winding current 50A/div

Primary winding current 50A/div

Secondary winding Voltage 350V/div

Secondary winding current $2 \mathrm{~A} / \mathrm{div}$

Current through Cv3

Current through Cv4

Voltage across Cd 200V/div

Voltage across secondary diode D2 200V/div

Fig.3 Observed waveforms in Operation Mode2 


\section{SWITCHING FREQUENCY VS. OUTPUT VOLTAGE}

Figures 4 (a) and (b) show the switching frequency fs vs. output voltage $V_{0}$ at the load resistance $\mathrm{RL}=617 \Omega$ and $\mathrm{RL}=1187 \Omega$, respectively, taking $\mathrm{Vi}$ as a parameter. The rated output voltage Vo is $350 \mathrm{~V}$. It is seen in Fig. 4 that the output voltage can be regulated sufficiently by changing the switching frequency fs.

\section{POWER EFFICIENCY}

By comparing the novel converter using the voltage doubler rectifier with the conventional one using the center tap rectifier, it is revealed that the proposed current resonance DC-DC converter with the voltage doubler rectifier has an excellent power efficiency characteristics in this chapter.

5-1 Proposed converter with the Voltage Doubler Rectifier

Fig.5 shows the power efficiency characteristics in the proposed converter with voltage doubler rectifier. It is seen in Fig.5 that the power efficiency is higher under the power condition from $100 \mathrm{~W}$ to $400 \mathrm{~W}$, when the input voltage $\mathrm{Vi}$ increases from $13 \mathrm{~V}$ to $19 \mathrm{~V}$, and that the maximum power efficiency is $97.4 \%$.

\section{5-2 Conventional converter with the Center Tap} Rectifier

Fig.6 shows the power efficiency characteristics in the conventional converter with the center tap rectifier. It is seen Fig.6 that the power efficiency of the conventional converter with the center tap rectifier is highest when Vi is $17 \mathrm{~V}$ and lowest when Vi is $19 \mathrm{~V}$. This phenomenon may be caused by the recovery loss of the rectifier diodes, which is shown in Fig.7. It seems that the recovery loss of the diode may become dominant at $\mathrm{Vi}=19 \mathrm{~V}$.

On the other hand, the recovery loss is very small and neglected in this proposed converter with voltage doubler rectifier, as shown in this Fig.8. also, the secondary winding resistance of the transformer in the proposed converter is one-eighth of that in the conventional one.

\section{CONCLUSION}

From the above discussion, it is concluded that as follows, (1) the proposed converter with the voltage doubler rectifier has the sufficiently high power efficiency(over $97.4 \%$ at maximum), comparing with that of the conventional one using the center tap rectifier. (2) the secondary winding resistance of the transformer in the proposed converter is one-eighth of that of the conventional one. (3)the recovery loss of the rectifier diode occurs in the conventional converter .However, it is very small and neglected in the proposed converter.

\section{REFERENCES}

[1]T.Kimura, Y. Miura, and T.Yatake, "Commercialization of the Residential Fuel Cell Cogeneration System---ENE FARM---“, The The Journal of Fuel Cell Technology, vol. 9, No.1, p. 49-53,July, 2009

[2]J-P. Vandelac and P. D. Ziogas: "A DC to DC PWM Series Resonant Converter Operated at Resonant Frequency", IEEE Trans. on IE,VOL.35, NO.3,August 1988.

[3]K. Jin and X. Ruan: "Hybrid Full Bridge Three Level LLC Resonant Converter - A Novel DC-DC Converter Suitable for Fuel Cell Power System", IEEE Trans.on IE, VOL. 53, NO.5, October 2006.

[4]K-H. Yi and G-W. Moon:"Novel Two-Phase Interleaved LLC Series-Resonant Converter Using a Phase of the Resonant Capacitor", IEEE Trans. On IE, VOL. 56, NO.5,May 2009 

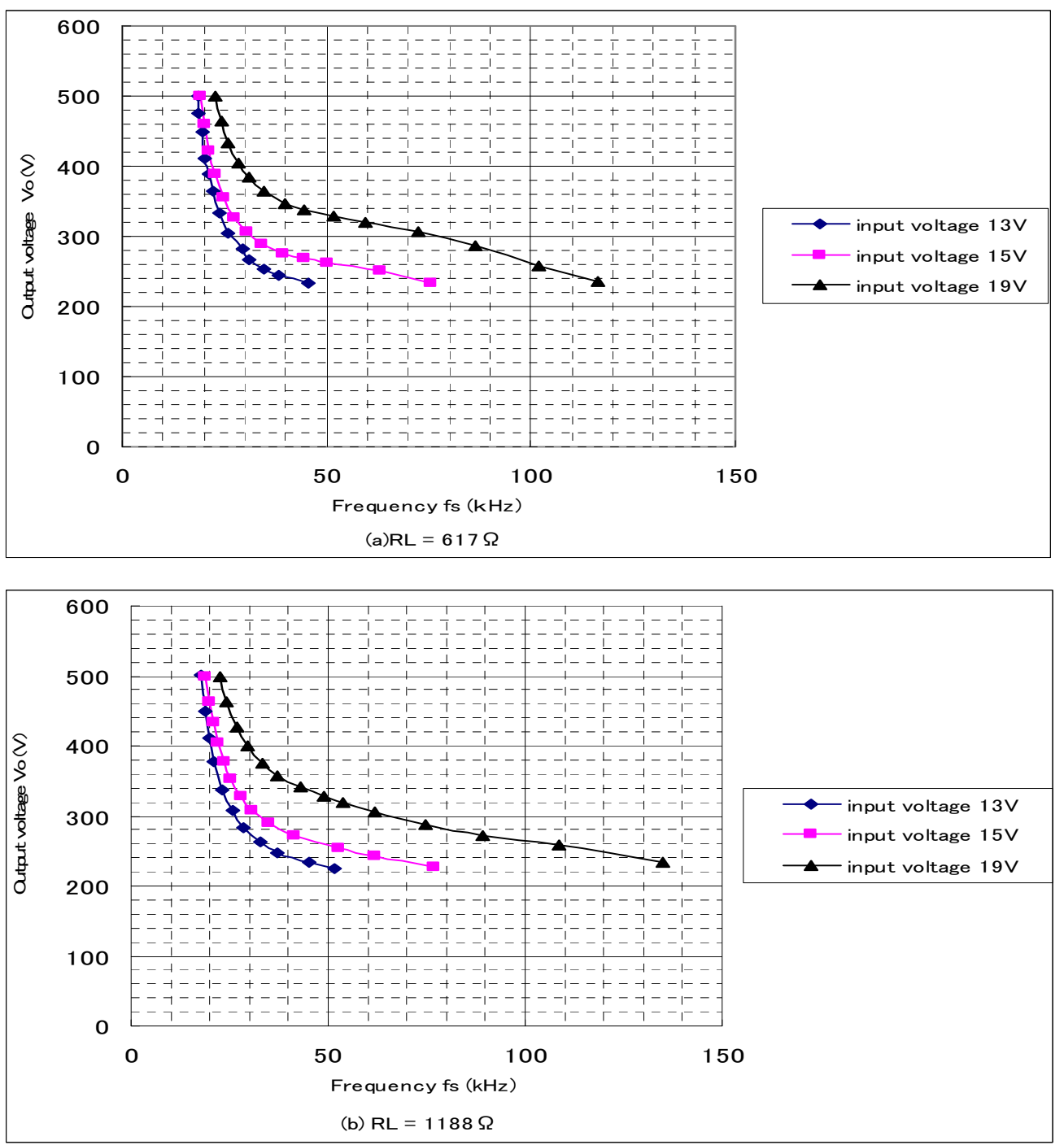

Fig.4. Switching frequency fs vs. output voltage Vo, taking Vi as a parameter.

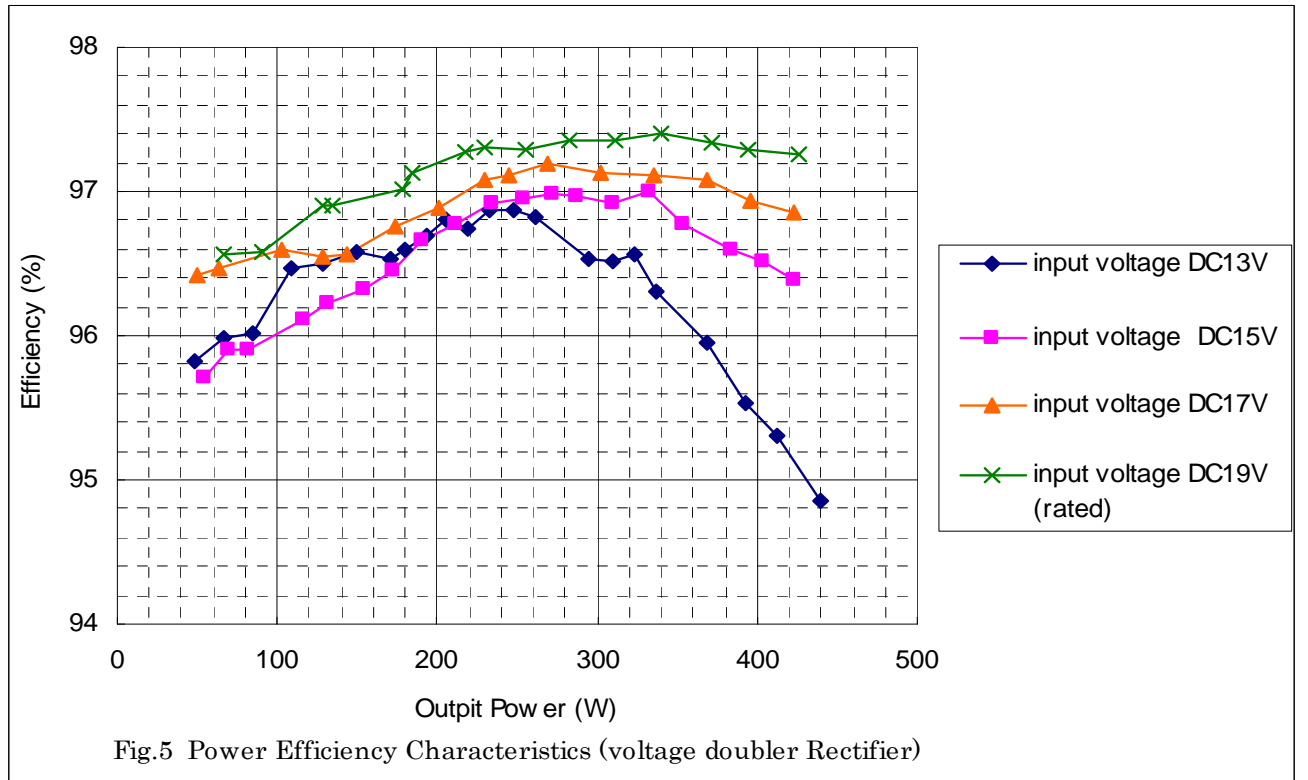



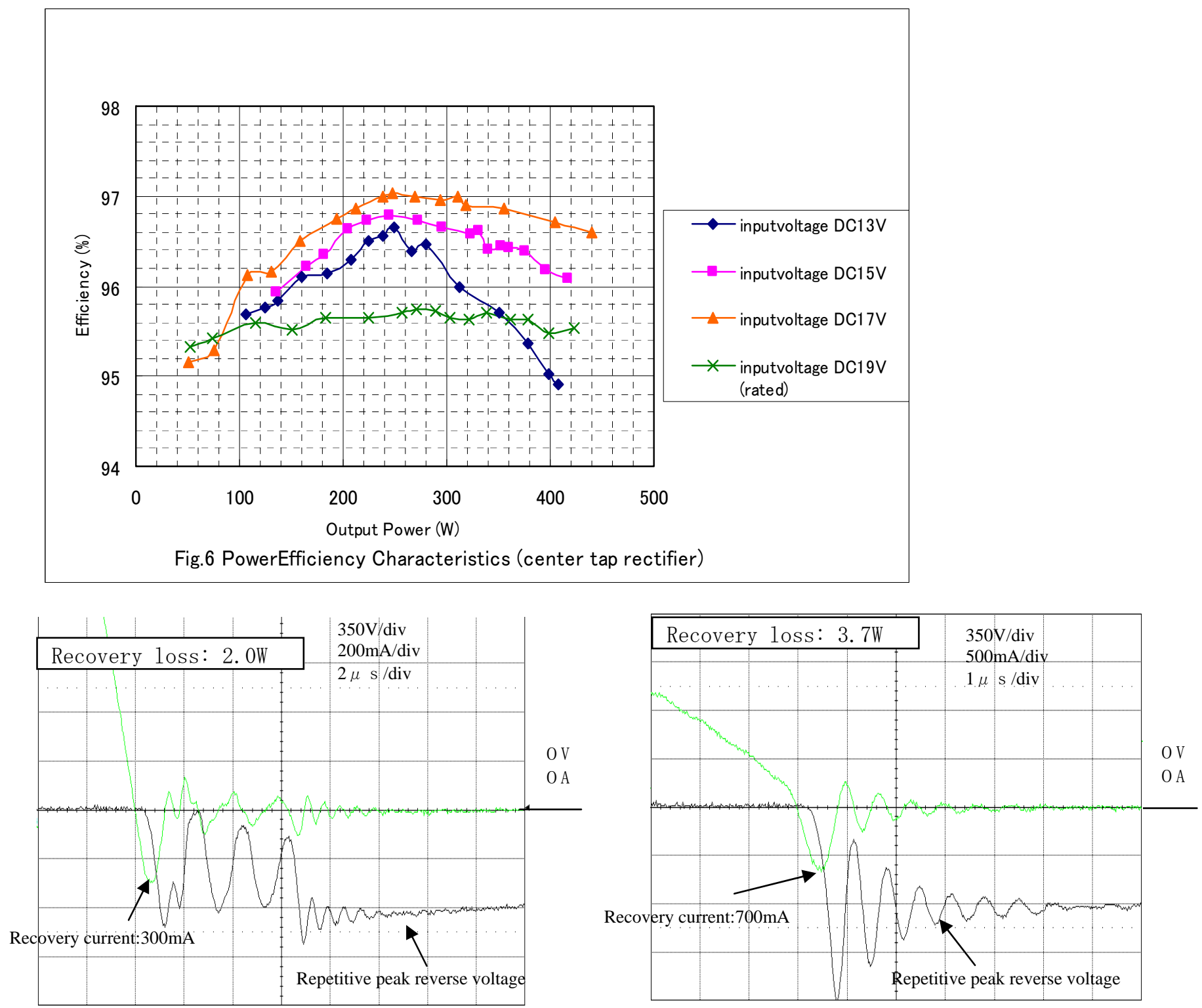

(a) $\mathrm{Vi}=17 \mathrm{~V}$

(b) $\mathrm{Vi}=19 \mathrm{~V}$

Fig.7 Recovery waveforms of the rectifier diode, when the output is $400 \mathrm{w}$ (center tap rectifier)

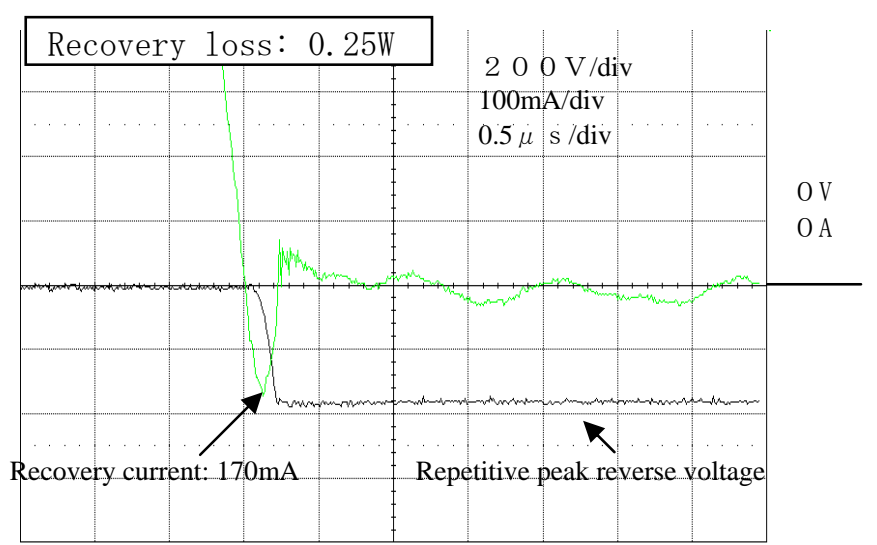

Fig. 8 Recovery waveforms of the rectifier diode, when the output is $400 \mathrm{w}$ (voltage doubler rectifier) 